\title{
Ethnic Specific body fat percent prediction equation as surrogate marker of obesity in Ethiopian adults
}

\author{
Makeda Sinaga $^{1 *}$, Melese Sinaga Teshome ${ }^{1}$, Tilhun Yemane ${ }^{2}$, Elsah Tegene ${ }^{3}$, David Lindtsrom ${ }^{4}$ and \\ Tefera Belachew ${ }^{1}$
}

\begin{abstract}
Background: Application of advanced body composition measurement methods is not practical in developing countries context due to cost and unavailability of facilities. This study generated ethnic specific body fat percent prediction equation for Ethiopian adults using appropriate data.

Methods: A cross-sectional study was carried ifrom February to April 2015 among 704 randomly selected adult employees of Jimma University. Ethnic specific Ethiopian body fat percent (BF\%) prediction equation was developed using a multivariable linear regression model with measured BF\% as dependent variable and age, sex, and body mass index as predictor variables. Agreement between fat percent measured using air displacement plethysmography and body fat percent estimated using Caucasian prediction equations was determined using Bland Altman plot.

Results: Comparison of ADP measured and predicted BF\% showed that Caucasian prediction equation underestimated body fat percent among Ethiopian adults by $6.78 \%(P<0.0001)$. This finding is consistent across all age groups and ethnicities in both sexes. Bland Altman plot did not show agreement between ADP and Caucasian prediction equation (mean difference $=6.7825$ ) and some of the points are outside $95 \%$ confidence interval. The caucasian prediction equation significantly underestimates body fat percent in Ethiopian adults, which is consistent across all ethnic groups in the sample. The study developed Ethnic specific BF\% prediction equations for Ethiopian adults.

Conclusion: The Caucasian prediction equation significantly underestimates body fat percent among Ethiopian adults regardless of ethnicity. Ethiopian ethnic-specific prediction equation can be used as a very simple, cheap, and cost-effective alternative for estimating body fat percent among Ethiopian adults for health care provision in the prevention of obesity and related morbidities and for research purposes.
\end{abstract}

Keywords: Body fat percent, Prediction, Equation, Ethiopia, Adults

\section{Introduction}

Measurement of body fat percent (BF\%) is useful to evaluate the effect of exercise and dietary interventions

\footnotetext{
* Correspondence: makedasinaga@gmail.com

${ }^{1}$ Department of Nutrition and Dietetics, Faculty of Public Health, Institute of Health, Jimma University, Jimma, Ethiopia

Full list of author information is available at the end of the article
}

in weight loss programs [1]. Although body mass index (BMI) is a simple tool used to identify the problem of obesity and risk of metabolic diseases [2], studies indicated that there are ethnic and racial differences in the utility of BMI in predicting BF\% [3-6]. One of the drawbacks is that BMI cannot differentiate two individuals with the same weight but different BF\% [7-9].

(c) The Author(s). 2021 Open Access This article is licensed under a Creative Commons Attribution 4.0 International License, which permits use, sharing, adaptation, distribution and reproduction in any medium or format, as long as you give appropriate credit to the original author(s) and the source, provide a link to the Creative Commons licence, and indicate if changes were made. The images or other third party material in this article are included in the article's Creative Commons licence, unless indicated otherwise in a credit line to the material. If material is not included in the article's Creative Commons licence and your intended use is not permitted by statutory regulation or exceeds the permitted use, you will need to obtain permission directly from the copyright holder. To view a copy of this licence, visit http://creativecommons.org/licenses/by/4.0/. The Creative Commons Public Domain Dedication waiver (http://creativecommons.org/publicdomain/zero/1.0/) applies to the data made available in this article, unless otherwise stated in a credit line to the data. 
This makes the validity and reliability of international BMI cutoff for the determination of body composition among different ethnic groups questionable. A metaanalysis showed that international BMI cutoff was not able to detect excess $\mathrm{BF} \%$ in half of the individuals [10]. It has been reported that measurement of $\mathrm{BF} \%$ gives a more precise estimation of body composition that BMI due to differences in body fat distributions among the different ethnic groups [11].

Several studies recommended $\mathrm{BF} \%$ to be a valid biomarker of obesity and risk of chronic noncommunicable diseases $[10,12-16]$. Since the past few decades the magnitude of non-communicable diseases (NCDs) is increasing in developing countries since the past few decades [17-19]. World Health Organization (WHO) projected that by 2030, the prevalence of chronic non-communicable diseases oversteps that of communicable diseases in sub-Saharan African countries including Ethiopia [18]. In Ethiopia, the prevalence of cardiovascular diseases (CVD) increased dramatically in the past few years with $31.5 \%$ of men and $28.9 \%$ of women in Addis Ababa having high blood pressure, indicating a "silent epidemic" of CVDs [20] accounting for over a third of deaths [21]. In Ethiopia, the problem is expected the worst scenario due to high prevalence of early life malnutrition associated with organ stunting [22].

Active surveillance of such epidemiologic transmission is required to prevent the double burden of both NCDs and infectious diseases [23]. Use of advanced methods of measuring biomarkers of obesity including body fat percent is impratical as they are too expensive for routine service use, require qualified personnel, and are not portable for use at the community level $[2,24]$.

Even though $\mathrm{BF} \%$ prediction equation was developed from body mass index using advanced techniques [11], the relationship and BMI and body fat percent varies based on ethnic backgrounds [25]. A meta-analysis showed that $\mathrm{BF} \%$ generated using Caucasian prediction equation significantly underestimated $\mathrm{BF} \%$ among Ethiopians, Thais, and Polynesians [5], which was hypothesized to be due to the differences in body build. However, the sample of Ethiopians involved in the study was very small making the estimations less reliable. In this study we set out to develop ethnic specific BF prediction equation and determine the agreement between the body fat percent measured by air displacement plethysmography and the Caucasian prediction equation among Ethiopian adults.

\section{Methods and materials}

The study was carried out among 704 employees of Jimma University who were selected randomly using their payroll as a sampling-frame. The university is located $357 \mathrm{~km}$ away from Addis Ababa in the southwest direction. It has six colleges and two institutes housing a total of 1341 academic and 5444 administrative staff. The sample size was calculated for developing cutoff values for obesity in the same study participants was used for this analysis. The study participants were selected from Jimma University due to high ethnic diversity compared to the general community in the surrounding. Administrative and academic staffs actively working and were not away for more than one week during recruitment period were considered for inclusion into the study.

Staff members with physical disability including deformity (kyphosis, scoliosis), pregnant women, and limb deformity that prevents them to stand erect and those who were seriously ill during the study period were excluded.

\section{Measurements}

WHO STEPS Questionnaire [26] was used to collect the data after adaptation to the local context. A stepwise approach was followed to collect socio-demographic data, anthropometric measurements, and body fat percent. Five clinical nurses used as data collectors and supervisors were given a 5-days intensive training on the interviewing approach, anthropometric measurements, and data recording before the actual data collection. All the measurements and interviews were done under close supervision.

\section{Anthropometry}

Body-weight was measured to the nearest $0.1 \mathrm{~kg}$ with a digital scale of the air displacement plethysmography (COSMED, Rome, Italy). The validity of the scale was checked using an object of a known weight every morning. Height was measured with an adjustable portable stadiometer which was accurate to $0.1 \mathrm{~cm}$ in a private place with the study participants wearing light clothing and their heads positioned at the Frankfert Plane and the four points (heel, calf, buttocks, and shoulders) touching the vertical stand and their shoes taken off. Before starting the measurements, the stadiometer was checked using a rod of known length. Body mass index (BMI) was calculated by dividing weight in kilograms by height in meters squared.

\section{Body fat percent (BF \%)}

Body fat percent was determined using air displacement plethysmography (COSMED, Rome, Italy) [27-29] after calibration of the machine for adults. The subjects wore a similar swimming pants and swimming cap covering the hair to prevent air trapping under clothing while all ADP tests were conducted. 
At the beginning of each testing day, quality-control procedures were performed. The participants were asked not eat or exercise and drink coffee $4-5 \mathrm{~h}$ prior to the test. They were also told not to smoke or drink alcohol within $2 \mathrm{~h}$, not to participate in vigorous/high-intensity weight training $12 \mathrm{~h}$ prior the test and were given advice to come after resting. For each participant, age, sex, height, and identifiers (ID) were entered into a computer. A two-step calibration procedure was then performed, first with the empty test chamber and then with a calibration cylinder. While the second calibration step was being performed, the subject was weighed on a calibrated electronic scale. Next, the participant was asked to sit inside the BOD POD chamber and instructed to remain still and continue normal breathing while the body volume was being measured. The measurement took two minutes and ADP was used in this study as the standard reference $( \pm 3 \%)$ of $\mathrm{BF} \%[30]$.

\section{Data analysis}

The questionnaire was checked for completeness by the investigator every day. Data were edited and doubly entered into EpiData version 3.1 and then exported to cleaned and analyzed using SPSS for Windows version 20. Descriptive analysis was conducted to describe the study subjects. Multivariable linear regression was used to determine the relationship between $\mathrm{BF} \%$ measured with ADP as the dependent variable and BMI, age, and sex as independent variables after checking all assumptions.

First, body fat percent prediction equations were generated for the different Ethnic groups. Differences between measured $\mathrm{BF} \%$ and the one predicted Caucasian equation were tested for significance by the paired twosided Student's $t$ test. All results were expressed as means with their standard deviations.

A Bland Altman plot was generated to determine the agreement between the $\mathrm{BF} \%$ measured using $\mathrm{ADP}$ and $\mathrm{BF} \%$ predicted by the $\mathrm{E}$ Caucasian prediction equations. The difference between measured $\mathrm{BF} \%$ and $\mathrm{BF} \%$ predicted by the Caucasian prediction equation was plotted on the $Y$-axis against its average on the $X$-axis. According to the recommendation, $95 \%$ of the data points should lie within the $\pm 1.96 \mathrm{SD}$ of the mean difference and mean difference should be at 0 point on the graph [31].

\section{Ethical consideration}

Before data collection, the study was approved by the Institutional Review Board of Jimma University College of Health Sciences. Written informed consent was also obtained from the study participants after the purpose of the study was clearly explained to all study participants. The right of study participants to refuse participation or withdraw from the study at any point was respected. All data were kept confidential and the study participants were informed that the information they gave will not be disclosed to the third person. To assure complete confidentiality, other identifying information including name were not recorded on questionnaire.

\section{Results}

Out of 705 samples planned, a total of 704 employees of Jimma University were involved in the study giving a response rate of $99.85 \%$. A little over half $(56.4 \%)$ were females and a larger proportion (38.2\%) of the study participants were in the age group between 20 and 30 followed by those in the age group of 31 and 40 years. The mean age $( \pm \mathrm{SD})$ was $34.7( \pm 9.5)$ years for males and $36.5( \pm 9.2)$ years for females. A large proportion of the study participants was Oromo (36.2\%) by ethnicity followed by Amhara (30.3\%).

The mean height $( \pm$ SD) was $171.8( \pm 13.4) \mathrm{cm}$ for males and $157.1( \pm 8.5) \mathrm{cm}$ for females. The mean weight was $66.0( \pm 11.7) \mathrm{kg}$ for males and $62.3( \pm 12.9)$ $\mathrm{kg}$ for females. The mean BMI was higher for females compared to males $\left(25.3 \mathrm{~kg} / \mathrm{m}^{2}\right.$ vs $\left.22.5 \mathrm{~kg} / \mathrm{m}^{2}\right)$. The measured body fat mass percent (mean $\pm \mathrm{SD}$ ) was $38.5 \%$ for females and $23.9 \%$ for males (Table 1).

Comparison of ADP measured and predicted $\mathrm{BF} \%$ showed that Caucasian prediction equation underestimated body fat percent among Ethiopian adults by 6.78\% $(P<0.0001)$. This finding is consistent across all age groups and ethnicities in both sexes. The underestimation was higher among males $(7.21 \%, P<0.0001)$ than females $(6.45 \%, P<0.0001)$. There was maximum underestimation among Gurage ethnicity $(8.53, P<0.0001)$ followed by Amhara (7.92\%, $P<0.0001)$, while the lowest underestimation was recorded among Yem (4.31) followed by Dawero ethnic groups $(5.08 \%, P<0.0001)$. The difference between measured and estimated BF\% using Caucasian prediction equation showed a significant variation with age. The highest difference $(7.59 \%, P$ $<0.0001$ ) was observed in the age group of $31-40$ years followed by those in the age group above 40 years (7.18\%, $P<0.0001)$ (Table 2).

As shown in Fig. 1, there is poor agreement between the $\mathrm{BF} \%$ using the Caucasian prediction equation as the mean difference is different from zero (mean difference $=6.7825$ ), and some of the points are outside the $95 \%$ confidence interval.

The ethnic specific body fat percent prediction equation were developed using linear regression based on body mass index, age, and sex as as presented in Table 3.

\section{Discussion}

The results demonstrated that Caucasian prediction equation significantly underestimates $\mathrm{BF} \%$ among 
Table 1 Background and anthropometric characteristics of the study participants $(n=704)$

\begin{tabular}{|c|c|c|}
\hline Characteristics & $n$ & Percent \\
\hline \multicolumn{3}{|c|}{ Sex } \\
\hline Female & 397 & 56.4 \\
\hline Male & 307 & 43.6 \\
\hline \multicolumn{3}{|c|}{ Ethnic groups } \\
\hline Oromo & 255 & 36.2 \\
\hline Amhara & 213 & 30.3 \\
\hline Gurage & 38 & 5.4 \\
\hline Kefa & 50 & 7.1 \\
\hline Others (Sidama, Wolaita, Tigre) & 48 & 6.8 \\
\hline Dawero & 57 & 8.1 \\
\hline Yem & 43 & 6.1 \\
\hline \multicolumn{3}{|c|}{ Age group (years) } \\
\hline $20-30$ & 269 & 38.2 \\
\hline $31-40$ & 250 & 35.5 \\
\hline \multirow[t]{2}{*}{$\geq 41$} & 185 & 26.3 \\
\hline & & Mean (SD) \\
\hline \multicolumn{3}{|c|}{ Height (cm) } \\
\hline Male & 307 & $171.8(13.4)$ \\
\hline Female & 397 & $157.1(8.5)$ \\
\hline \multicolumn{3}{|c|}{ Weight (kg) } \\
\hline Male & 307 & $66.0(11.7)$ \\
\hline Female & 397 & $62.3(12.9)$ \\
\hline \multicolumn{3}{|c|}{ BMI $\left(\mathrm{kg} / \mathrm{m}^{2}\right)$} \\
\hline Female & 397 & $25.3(5.1)$ \\
\hline Male & 307 & $22.5(3.9)$ \\
\hline Total & 704 & $24.1(4.8)$ \\
\hline \multicolumn{3}{|c|}{ ADP measured body fat mass fat $\%$ (mean $\pm \mathrm{SD})$} \\
\hline Female & 397 & $38.5(10.1)$ \\
\hline Male & 307 & $23.9(9.2)$ \\
\hline
\end{tabular}

$S D$ standard deviation, $\mathrm{kg}$ kilogram, $A D P$ air displacement plethysmography

Ethiopian adults, which is consistent with the finding reported from a study conducted among adult population of different ethnic groups [5]. It was also reported that body-mass index (BMI) may misclassify subgroups with excess body fat among the different races and genders significantly [3]. Different levels in energy intake and energy expenditure and in body build and body frame could be possible explanations for underestimation of $\mathrm{BF}$ $\%$ by the Caucasian equation [6]. Differences in body build have also been reported within Caucasian populations [5, 32, 33].

Ethiopian ethnic-specific prediction equation showed the best estimate of $\mathrm{BF} \%$. Ethiopian general prediction equation worked well but does not predict $\mathrm{BF} \%$ for some ethnicities like Amharae and Yem for which there were significant differences between BF\% measured by ADP and that estimated using the prediction equation. There was no statistically significant difference $(P>0.05)$ between measured body fat and predicted body fat using ethnic-specific prediction equations. Our findings showed that the Caucasian prediction equation underestimated body fat percent of Ethiopian adults when validated against ADP, which is considered to be an accurate method in healthy adults [34]. The Bland Altman plot [31] also showed that the differences plotted on the $Y$-axis against the average of measured fat and predicted fat on the $X$-axis showed that $95 \%$ confidence interval did not include all the points and the mean difference is greater than zero showing the Caucasian prediction equation underestimates body fat percent. Thus, the Ethiopian prediction equation could be used to identify $\mathrm{BF} \%$ as a modifiable risk factor, manage patients, and develop guidelines for control and prevention of obesity and related non-communicable diseases in Ethiopia.

Subjects with a small body frame are likely to have a relatively lower fat-free mass (due to lower muscle mass) compared to other people of the same body height and hence BMI is likely to underestimate their body fat when the prediction equation developed in subjects with a bigger body build is applied $[5,6,33]$. The reason for the different relationships between body fat and BMI in the different populations is unknown. Apart from differences between dietary patterns and differences in physical activity, variations in body build may be an important contributor [33, 35]. It has been shown that the relation between body fat percent and MBI is curvilinear [36] indicating that $\mathrm{BMI}$ underestimates $\mathrm{BF} \%$ even more for very obese subjects.

Differences in the relative leg length lead to differences in body fat percent for the same BMI such that people with lower sitting height to height ratio (people with longer legs relative trunk) have lower body fat percent [37]. It is known that there are differences in relative sitting height between Caucasians and Blacks, and between Caucasians and Asians, with blacks having relatively longer legs and Asians having relatively shorter legs [35, 38]. Apart from relative leg length, a stocky or slender body build may be one of the explanations for the difference [6]. A stocky person is expected to have more muscle mass compared to a slender person of the same body height $[6,39]$. As Ethiopians have a slender body build, the Caucasian equation could underestimate their body fat percent. Thus, for the same BMI, the slender person will have more body fat [38]. Additional anthropometric measures may be necessary to improve the quality of the BMI as an indicator of body fatness among ethnic groups $[5,33,38]$. 
Table 2 Differences between measured and predicted body fat percentages using Caucasian prediction equations among Ethiopian Adult employs of Jimma University

\begin{tabular}{|c|c|c|c|c|c|}
\hline \multirow[t]{2}{*}{ Variables } & \multirow[t]{2}{*}{$n$} & \multicolumn{4}{|c|}{ Measured body fat $\%$ - predicted body fat $\%$ using Caucasian prediction equation ${ }^{a}$} \\
\hline & & $\begin{array}{l}\text { Measured, body } \\
\text { fat } \%\end{array}$ & $\begin{array}{l}\text { Caucasian equation, predicted body fat } \\
\%\end{array}$ & Difference & $P^{*}$ \\
\hline \multicolumn{6}{|c|}{ Sex } \\
\hline Male & 307 & 23.86 & 18.7764 & 7.2153 & $\begin{array}{l}< \\
0.0001\end{array}$ \\
\hline Female & 397 & 38.47 & 33.3513 & 6.4478 & $\begin{array}{l}< \\
0.0001\end{array}$ \\
\hline Total & 704 & 32.10 & 26.99550 & 6.7825 & $\begin{array}{l}< \\
0.0001\end{array}$ \\
\hline \multicolumn{6}{|c|}{ Ethnicity } \\
\hline Oromo & 255 & 29.02 & 23.9985 & 6.8420 & $\begin{array}{l}< \\
0.0001\end{array}$ \\
\hline Amhara & 213 & 36.56 & 30.1531 & 7.9221 & $\begin{array}{l}< \\
0.0001\end{array}$ \\
\hline Gurage & 38 & 35.05 & 28.1747 & 8.5323 & $\begin{array}{l}< \\
0.0001\end{array}$ \\
\hline Kefa & 50 & 33.96 & 29.7953 & 5.7637 & $\begin{array}{l}< \\
0.0001\end{array}$ \\
\hline Dawero & 57 & 31.49 & 28.1145 & 5.0774 & $\begin{array}{l}< \\
0.0001\end{array}$ \\
\hline Yem & 43 & 29.12 & 26.5283 & 4.3102 & $\begin{array}{l}< \\
0.0001\end{array}$ \\
\hline Others $^{b}$ & 48 & 27.77 & 24.1443 & 5.3252 & $\begin{array}{l}< \\
0.0001\end{array}$ \\
\hline Total & 704 & 32.10 & 26.9955 & 6.7825 & $\begin{array}{l}< \\
0.0001\end{array}$ \\
\hline \multicolumn{6}{|c|}{ Age group } \\
\hline $20-30$ & 269 & 25.55 & 21.43 & 5.7647 & $\begin{array}{l}< \\
0.0001\end{array}$ \\
\hline $31-40$ & 250 & 35.71 & 29.62 & 7.5860 & $\begin{array}{l}< \\
0.0001\end{array}$ \\
\hline$\geq 41$ & 185 & 36.75 & 31.54 & 7.1767 & $\begin{array}{l}< \\
0.0001\end{array}$ \\
\hline Total & 704 & 32.10 & 27.00 & 6.7825 & $\begin{array}{l}< \\
0.0001\end{array}$ \\
\hline
\end{tabular}

Due to the unavailability of the standard portable machine for the measurement of $\mathrm{BF} \%$, equations such as the one developed by this study are very important to calculate the body fat percent for each ethnicity. Assessment of body fat percent at the community level is important for public health policies to detect the magnitudes of overweight and obesity. In recent years, there have been numerous studies conducted to find out the best anthropometric indicator for detecting body fatness among different population groups [40-44].

The fact that there are ethnic and racial differences in the predictive power of BMI-based equation has been reported [5, 33, 38]. The need for developing ethnicspecific prediction equations has been suggested to avoid such a problem [38]. The findings, have practical implications in the wake of an increasing level of obesity due to the tendency of urbanization, dietary transition, increasing consumption of more processed foods, and transition into a motorized way of life. This needs a simple tool for early detection and public health interventions, as the facilities for determination of body fat precept like ADP are expensive and non-portable, which make them unavailable for day to day service provision. Therefore, the development of body fat percent prediction equation based on locally relevant data is a critical input to such prevention efforts. This is especially important as Ethiopia is aspiring to be a middle-income country by 2025 , life expectancy has risen to 64 years, 


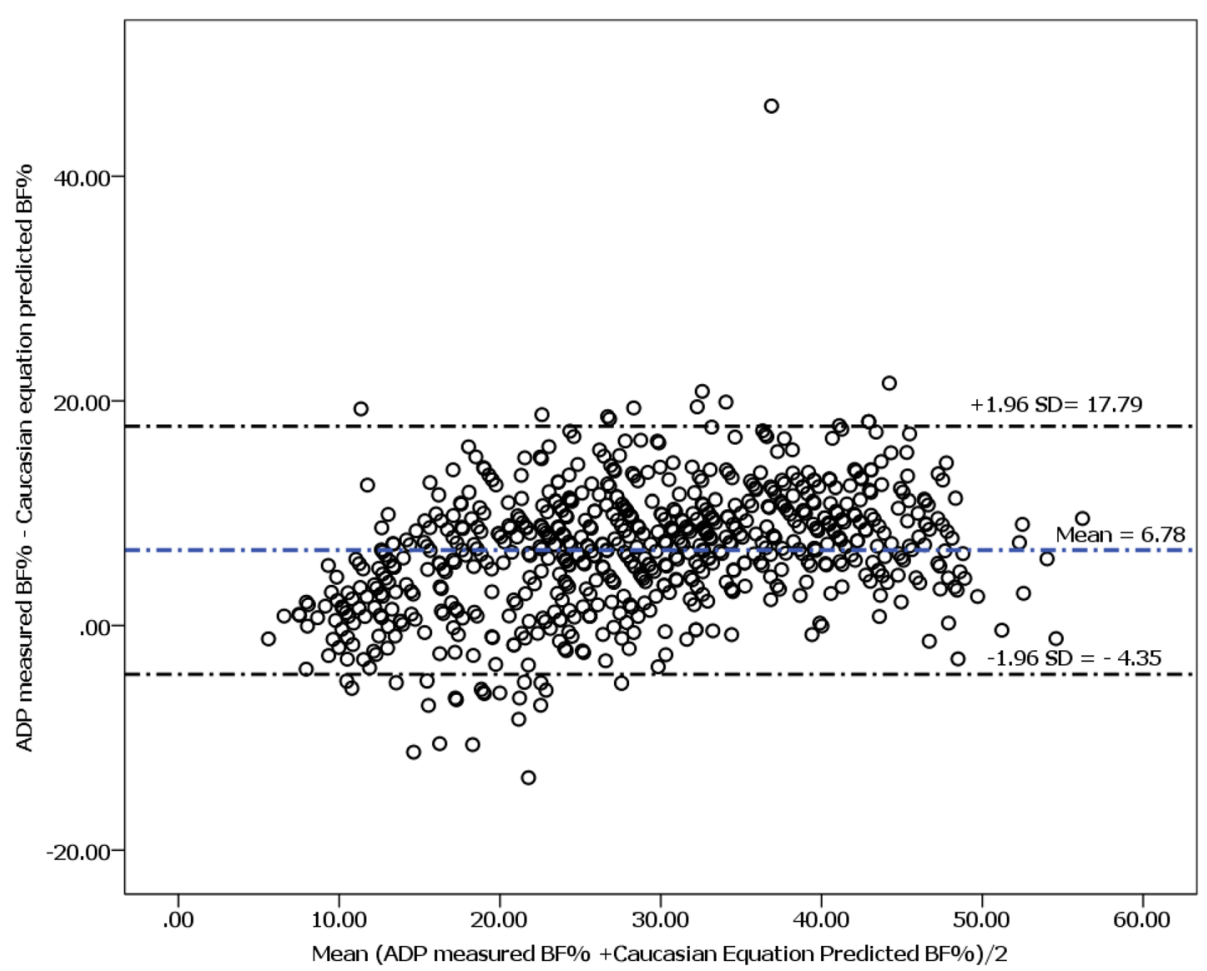

Fig. 1 Bland Altman plot showing the agreement between ADP measured body fat percent and body fat percent estimated using Caucasian prediction equation among Ethiopian adults

and there is an increasing prevalence of chronic noncommunicable diseases related to obesity $[45,46]$. Prevention of NCDs will enable the country to reap its demographic dividend by avoiding untimely death and disability among working adults [47].

The current study has the strength of using a large sample size and developing the prediction equation for the different ethnic groups. Although getting a sample of all ethnicities in Ethiopia was difficult given the nonportable nature of the ADP, the study tried to include the ethnicities that constitute the majority of the population.

The fact that the study used local data for the development of a prediction equation and ADP as the gold standard for measuring body fat percent are some of the strengths. Although Ethiopian prediction equation was developed using a multiethnic sample (training group) future research should validate its performance in estimating body fat percent in a different sample of multiethnic composition (testing group).

Table 3 Multivariable linear regression model predicting body fat mass percent (BF \%) as a dependent variable and body mass index (BMI), age, and sex as independent variables for different ethnic groups of Ethiopia

\begin{tabular}{|c|c|c|c|c|c|c|c|c|c|c|}
\hline \multirow[t]{2}{*}{ Sample } & \multirow[t]{2}{*}{$n$} & \multicolumn{2}{|l|}{ BMI } & \multicolumn{2}{|l|}{ Age } & \multicolumn{2}{|l|}{ Sex } & \multicolumn{2}{|l|}{ Intercept } & \multirow{2}{*}{$\begin{array}{l}\text { Adjusted } \\
R^{2}\end{array}$} \\
\hline & & $\bar{\beta}$ & SE & $\bar{\beta}$ & SE & $\bar{\beta}$ & SE & $\bar{\beta}$ & SE & \\
\hline Oromo & 255 & 1.421 & 0.085 & 0.261 & 0.040 & -11.106 & 0.794 & -6.340 & 2.271 & 0.785 \\
\hline Amhara & 213 & 1.367 & 0.069 & 0.213 & 0.040 & -10.600 & 0.713 & -2.721 & 2.104 & 0.825 \\
\hline Gurage & 38 & 1.575 & 0.250 & 0.266 & 0.101 & -7.974 & 1.866 & -10.291 & 5.918 & 0.751 \\
\hline Kefa & 50 & 1.779 & 0.234 & 0.292 & 0.104 & -10.738 & 2.111 & -17.622 & 1.866 & 0.708 \\
\hline Dawero & 57 & 1.641 & 0.266 & 0.156 & 0.117 & -6.791 & 2.423 & -10.774 & 6.879 & 0.526 \\
\hline Yem & 43 & 1.683 & 0.172 & 0.148 & 0.068 & -9.977 & 1.646 & -10.961 & 4.420 & 0.788 \\
\hline Others $^{a}$ & 48 & 1.606 & 0.172 & 0.124 & 0.099 & -8.531 & 1.646 & -9.265 & 4.785 & 0.728 \\
\hline
\end{tabular}

Where sex (male $=1$, female $=0$ )

$B M I$ body mass index, $S E$ standard error

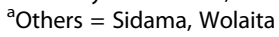




\section{Conclusion}

The Caucasian prediction equation significantly underestimates body fat percent among Ethiopian adults. As advanced methods such as ADP are neither available nor portable for use at the community level, the Ethiopian ethnic specific prediction equation can be used as a very simple cheap effective alternative for estimating body fat percent among Ethiopian adults for health care provision and research purposes.

\section{Acknowledgements}

We appreciate the Institute of Health, Jimma University, for funding the study and JUCAN project and Mettu Karl Hospital for providing body composition analyses and laboratory facilities for lipid profiles analyses, respectively. We are also grateful to the study participants for their willingness involved in the study.

\section{Authors' contributions}

MS and TB conceived and planned the study. MS, MST, TY, TB, and ET implemented the study. MS and TB did the analyses. MS drafted the manuscript. MST, TY, TB, ET, and DL critically reviewed the manuscript. All authors gave input to the manuscript and read and approved the final version.

\section{Funding}

The study was funded by Jimma University, Institute of Health. The Institute did not have a role in the design of the study and collection, analysis, and interpretation of data or in writing the manuscript.

\section{Availability of data and materials}

The datasets used and/or analyzed during the current study are available from the corresponding author on reasonable request.

\section{Ethics approval and consent to participate}

Ethical clearance was obtained from Jimma University Institutional Review Board (IRB). Clinical directors, administration office, and college deans were informed about the study objectives through a letter written from Jimma University IRB office to enhance cooperation. Written consent was taken from each selected participant to confirm willingness after the explanation of the survey purpose, description of the benefits. The study participants were assured that they are free to withdraw their consent and discontinue participation without any form of prejudice. Privacy and confidentiality of collected data was ensured throughout the study.

\section{Consent for publication}

Not applicable.

\section{Competing interests}

Authors do not have any competing interests.

\section{Author details}

${ }^{1}$ Department of Nutrition and Dietetics, Faculty of Public Health, Institute of Health, Jimma University, Jimma, Ethiopia. ${ }^{2}$ Department of Laboratory and Biomedical Sciences, Faculty of Health Sciences, Institute of Health, Jimma University, Jimma, Ethiopia. ${ }^{3}$ Department of Internal Medicine, Faculty of Medicine, Institute of Health, Jimma University, Jimma, Ethiopia. ${ }^{4}$ Department of Sociology, Brown University, Providence, USA.

Received: 27 March 2018 Accepted: 7 January 2021

Published online: 09 April 2021

\section{References}

1. Yulong Li Validity of non-invasive methods for body composition measurements in older adults lowa State University 2012. Availabke from: https://lib.dr.iastate.edu/cgi/viewcontent.cgi?article=3605\&context=etd,

2. Ramírez-Vélez R, Correa-Bautista JE, Sanders-Tordecilla A, Ojeda-Pardo ML, Cobo-Mejía EA, Castellanos-Vega RDP, et al. Percentage of body fat and fat mass index as a screening tool for metabolic syndrome prediction in
Colombian University students. Nutrients. 2017;9(9). https://doi.org/10.3390/ nu9091009.

3. Carpenter CL, Yan E, Chen S, Hong K, Arechiga A, Kim WS, et al. Body fat and body-mass index among a multiethnic sample of college-age men and women. J Obes. 2013;2013:790654. https://doi.org/10.1155/2013/790654 Epub 2013 Apr 8.

4. Rothman KJ. BMI-related errors in the measurement of obesity. Int J Obes (Lond). 2008;32(Suppl 3):S56-9. https://doi.org/10.1038/ijo.2008.87.

5. Deurenberg P, Yap M, van Staveren WA. Body mass index and percent body fat: a meta-analysis among different ethnic groups. Int J Obes Relat Metab Disord. 1998;22(12):1164-71.

6. Gurrici S, Hartriyanti Y, Hautvast JG, Deurenberg P. Differences in the relationship between body fat and body mass index between two different Indonesian ethnic groups: the effect of body build. Eur J Clin Nutr. 1999; 53(6):468-72.

7. Rahman M, Berenson $A B$. Racial difference in lean mass distribution among reproductive-aged women. Ethn Dis. 2010;20(4):346-52.

8. Abel R-C, Somers VK, Sierra-Johnson J, Thomas RJ, Bailey KR, Collazo-Clavell $\mathrm{ML}$, et al. Accuracy of body mass index to diagnose obesity in the US adult population. Int J Obes (Lond). 2008;32(6):959-66.

9. Nti H, Steiner-Asiedu M, Anderson AK. Percent body fat versus body mass index among Ghanaian adults in different districts. Int J Nutr Food Sci. 2014; 3(6):586-91.

10. Zeng Q, Dong S-Y, Sun X-N, Xie J, Braz YC, et al. J Med Biol Res. 2012;45(7): 591-600Published online 2012 Apr 20. https://doi.org/10.1590/S0100$879 \times 2012007500059$

11. Silva DAS, Petroski EL, Peres MA. Is high body fat estimated by body mass index and waist circumference a predictor of hypertension in adults? A population-based study. Nutr J. 2012;11:112.

12. Zeng Q, Dong SY, Sun XN, Xie J, Cui Y. Percent body fat is a better predictor of cardiovascular risk factors than body mass index. Braz J Med Biol Res. 2012:45(7):591-600 Epub 2012 Apr 19.

13. Williams SCP. Link between obesity and cancer. PNAS. 2013;110(22):8753-4.

14. Allott EH, Hursting SD. Obesity and cancer: mechanistic insights from transdisciplinary studies. Endocr Relat Cancer. 2015;22(6):R365-86.

15. Shoelson SE, Lee J, Goldfine AB. Inflammation and insulin resistance. J Clin Invest. 2006;116(7):1793-801.

16. Kaur J. A comprehensive review on metabolic syndrome. Cardiol Res Pract. 2014;2014:943162. https://doi.org/10.1155/2014/943162.

17. Moges B, Amare B, Fantahun B, Kassu A. High prevalence of overweight, obesity, and hypertension with increased risk to cardiovascular disorders among adults in Northwest Ethiopia: a cross sectional study. BMC Cardiovasc Disord. 2014;14:155Published online 2014 Nov 5. https://doi.org/ 10.1186/1471-2261-14-155.

18. WHO. Global status report on non-communicable diseases; 2010. Available from: http://www.who.int/nmh/publications/ncd_report_full_en.pdf. Accessed on: 2 Dec 2017

19. Ellulu M, Abed Y, Rahmat A, Ranneh Y, Ali F. Epidemiology of obesity in developing countries: challenges and prevention. HOAJ. 2014; Available from: http://www.hoajonline.com/journals/pdf/2052-5966-2-2.pdf. Accessed on 2 Dec 2017.

20. Wai WS, Dhami RS, Gelaye B, Girma B, Lemma S, Berhane Y, et al. Comparison of measures of adiposity in identifying cardiovascular disease risk among Ethiopian adults. Obesity (Silver Spring). 2012;20(9):1887-95. https://doi.org/10.1038/oby.2011.103.

21. World Health Organization. Noncommunicable diseases country profiles; 2011. http://apps.who.int/iris/bitstream/10665/44704/1/9789241502283_eng.pdf

22. Calkins K, Devaskar SU. Fetal origins of adult disease. Curr Probl Pediatr Adolesc Health Care. 2011;41(6):158-76. https://doi.org/10.1016/j.cppeds. 2011.01.001.

23. Agyei-Mensah S, de Graft Aikins A. Epidemiological transition and the double burden of disease in Accra, Ghana. J Urban Health. 2010;87(5):879_ 97. https://doi.org/10.1007/s11524-010-9492-y

24. Newton RL, Alfonso A, White MA, York-Crowe $\mathrm{E}$, Walden $\mathrm{H}$, Ryan D, et al. Percent body fat measured by BIA and DEXA in obese, African-American adolescent girls. Int J Obes (Lond). 2005;29:594-602. https://doi.org/10.1038/ sj.ijo.0802968

25. Kalra S, Mercuri M, Anand SS. Measures of body fat in south Asian adults. Nutr Diabetes. 2013;3:e69. https://doi.org/10.1038/nutd.2013.10.

26. World Health Organization. The WHO STEPwise approach to Surveillance of non-communicable diseases (STEPS): non-communicable diseases and 
mental health 20 Avenue Appia, 1211 Geneva 27, Switzerland, 2003. Available from: http://www.who.int/ncd_surveillance/en/steps_framework_ dec03.pdf., accessd on 23 Nov 2015.

27. Hames KC, Anthony SJ, Thornton JC, Gallagher D, Goodpaster BH. Body composition analyses by air displacement plethysmography in adults ranging from normal weight to extremely obese. Obesity (Silver Spring). 2014;22(4):1078-84.

28. Fields DA, Higgins PB, Hunter GR. Assessment of body composition by airdisplacement plethysmography: influence of body temperature and moisture. Dyn Med. 2004:3:3. https://doi.org/10.1186/1476-5918-3-3.

29. Dempster P, Aitkens S. A new air displacement method for the determination of human body composition. MedSci Sports Exerc. 1995; 27(12):1692-7

30. Reinert BL, Pohlman R, Hartzler L. Correlation of air displacement plethysmography with alternative body fat measurement techniques in men and women. Int J Exerc Sci. 2012;5(4):367-78 eCollection 2012.

31. Giavarina D. Understanding bland Altman analysis. Biochem Med. 2015; 25(2):141-51.

32. Rush EC, Freitas I, Plank LD. Body size, body composition and fat distribution: comparative analysis of European, Maori, Pacific Island and Asian Indian adults. Br J Nutr. 2009:102(4):632-41. https://doi.org/10.1017/ S0007114508207221 Epub 2009 Feb 10. http://dx.doi.org/10.11613/BM.2015. 015.

33. Deurenberg P, Yap DM, Wang J, Lin FP, Schmidt G. The impact of body build on the relationship between body mass index and percent body fat. Int J Obes (Lond). 1999;23:53-542.

34. Biaggi RR, Vollman MW, Nies MA, Brener CE, Flakoll PJ, Levenhagen DK, et al. Comparison of air-displacement plethysmography with hydrostatic weighing and bioelectrical impedance analysis for the assessment of body composition in healthy adults. Am J Clin Nutr. 1999;69(5):898-903.

35. Heymsfield SB, Peterson CM, Thomas DM, Heo M, Schuna JM Jr. Why are there race/ethnic differences in adult body mass index-adiposity relationships? A quantitative critical review. Obes Rev. 2016;17(3):262-75. https://doi.org/10.1111/obr.12358.

36. Ranasinghe C, Gamage P, Katulanda P, Andraweera N, Thilakarathne S, Tharanga P. Relationship between body mass index (BMI) and body fat percentage, estimated by bioelectrical impedance, in a group of Sri Lankan adults: a cross sectional study. BMC Public Health. 2013;13:797.

37. Bogin B, Bedoun $\mathrm{N}$. The relationship of sitting height ration to body mass index and fatness in the United States. Human Ecol Special Issue. 2007;15:18.

38. Deurenberg-Yap M, Schmidt G, van Staveren WA, Deurenberg P. The paradox of low body mass index and high body fat percentage among Chinese, Malays and Indians in Singapore. Int J Obes (Lond). 2000;24:10117 .

39. Norgan NG. Population differences in body composition in relation to the body mass index. Eur J Clin Nutr. 1994;48(Suppl 3):S10-25 discussion S26-7.

40. Nguyen TT, Adair LS, He K, Popkin BM. Optimal cutoff values for overweight: using body mass index to predict incidence of hypertension in 18- to 65year-old Chinese adults. J Nutr. 2008;138(7):1377-82.

41. Lin WY, Lee LT, Chen CY, Lo H, Hsia HH, Liu IL, et al. Optimal cut-off values for obesity: using simple anthropometric indices to predict cardiovascular risk factors in Taiwan. Int J Obes Relat Metab Disord. 2002;26(9):1232-8.

42. Kim SH, Choi H, Won CW, Kim B-S. Optimal cutoff points of anthropometric parameters to identify high coronary heart disease risk in Korean adults. J Korean Med Sci. 2016;31:61-6.

43. Zaher ZM, Zambari R, Pheng CS, Muruga V, Ng B, Appannah G, et al. Optimal cut-off levels to define obesity: body mass index and waist circumference, and their relationship to cardiovascular disease, dyslipidaemia, hypertension and diabetes in Malaysia. Asia Pac J Clin Nutr. 2009:18(2):209-16.

44. Snehalatha C, Viswanathan V, Ramachandran A. Cutoff values for normal anthropometric variables in Asian Indian adults. Diabetes Care. 2003;26: 1380-4.

45. Misganaw A, Haile Mariam D, Ali A, Araya T. Epidemiology of major noncommunicable diseases in Ethiopia: a systematic review. J Health Popul Nutr. 2014;32(1):1-13.

46. Abebe SM, Andargie G, Shimeka A, et al. The prevalence of noncommunicable diseases in Northwest Ethiopia: survey of Dabat health and demographic surveillance system. BMJ Open. 2017;7:e015496. https://doi. org/10.1136/bmjopen-2016-015496
47. WHO. Health, economic growth, and poverty reduction. The report of working group 1 of the commission on macroeconomics and health; 2002. Available from : http://apps.who.int/iris/bitstream/10665/42492/1/92415 90092.pdf

\section{Publisher's Note}

Springer Nature remains neutral with regard to jurisdictional claims in published maps and institutional affiliations.

\section{Ready to submit your research? Choose BMC and benefit from:}

- fast, convenient online submission

- thorough peer review by experienced researchers in your field

- rapid publication on acceptance

- support for research data, including large and complex data types

- gold Open Access which fosters wider collaboration and increased citations

- maximum visibility for your research: over $100 \mathrm{M}$ website views per year

At BMC, research is always in progress.

Learn more biomedcentral.com/submissions 